\title{
The methodic of calculation for the need of basic construction machines on construction site when developing organizational and technological documentation
}

\author{
Boris Zhadanovsky ${ }^{1}$ and Sergey Sinenko ${ }^{1 *}$ \\ ${ }^{1}$ Moscow State University of Civil Engineering, Yaroslavskoe shosse, 26, Moscow, 129337, Russia
}

\begin{abstract}
Economic indicators of construction work, particularly in highrise construction, are directly related to the choice of optimal number of machines. The shortage of machinery makes it impossible to complete the construction \& installation work on scheduled time. Rates of performance of construction \& installation works and labor productivity during high-rise construction largely depend on the degree of provision of construction project with machines (level of work mechanization). During calculation of the need for machines in construction projects, it is necessary to ensure that work is completed on scheduled time, increased level of complex mechanization, increased productivity and reduction of manual work, and improved usage and maintenance of machine fleet. The selection of machines and determination of their numbers should be carried out by using formulas presented in this work.
\end{abstract}

\section{Introduction}

The shortage or surplus of machines for construction $\&$ installation works significantly affect economic indicators of functioning in construction companies. The rate and quality of construction \& installation works and labor productivity largely depend on the technical level of mechanization, as well as the degree of provision of the construction project with machines (level of labor mechanization).

To determine the need for machines for construction it is necessary to consider:

- completion of work on objects in accordance with the scheduled time;

- increasing level of complex mechanization of construction and installation works;

- increasing labor productivity and reducing the proportion of manual labor;

- application of progressive work production methods;

- improving the usage of existing fleet of machines;

- provision of the machine fleet with required rate of renewal.

\footnotetext{
${ }^{*}$ Corresponding author: SlavinaAY@mgsu.ru
} 


\section{Methods}

Calculation of demand and supply of the machines to construction companies needs to account for the production by these organizations of the whole complex of organizational, technological and operational activities aimed at continuous improvement of efficient use of the machine fleet $[1,2,7,8,9,10]$.

The need to calculate the demand of construction machines arises at the following levels of planning construction work when determining:

- need for machines during development of work execution design for the construction of a specific object;

- need for machines on the construction \& installation works program by a separate construction organization (trust, mechanization management);

- need and justification of supply requests for the supply of machines to construction departments or to the construction industry in whole.

The methodology for determining need of machines for these planning levels is based on the same approach and varies in detail and in the amount of input data. In the first case, the source of the initial data for the calculations is the organizational and technological documentation and in other cases, the average data of construction projects (organizations) submitted statistical data during the base period (a year).

Formation of the construction machine fleet should be carried out starting with the process of selecting the means of mechanization during preparation of work execution design (PPR) for the construction object and further on the hierarchical structure of management in planning of the development of the machine fleet at the level of trust (department) of mechanization, and the ministry (authorities) [1, 3, 4, 5].

Determination of the need for machines in the construction industry should also begin with the lowest level (object) and reach final form at the highest level of management (construction ministry).

Determining the need for machines at different levels of fleet formation has its own characteristics both in methodical approach and in concrete terms, i.e. the need per unit of work (pieces, $\mathrm{m}^{3}, \mathrm{~m}^{2}$, etc.), or per 1 million rubles of construction and installation work (SMR). This considers specifics of functioning and purpose of the construction machine fleet (fleet of the construction object, fleet of the company or fleet of the ministry).

As noted above, methodological approach in determining the need of machines for the construction object, the trust (department) of mechanization, and the ministry (authorities) has differences in determination of the initial data and in formation of basic information.

When determining the need of construction machines for the construction object (by construction object we mean separately constructed buildings and structures, for example a residential building, a factory) specific operating conditions are considered, which are expressed in variation of ground soil, number of storeys of buildings, cargo size, and real physical volumes of work tied to this object with distribution in their structure (trenches, construction pits, excavations, etc.). In addition, usage time of the machine on the construction object can vary from a few days to several months. After performing a certain amount of work the machine is no longer needed and it can be used on another object, in other operating conditions.

For machines used with one type of work equipment the operating conditions at different sites can differ on many technological factors. For universal construction machinery, which has several types of changeable work equipment, the number of technological factors that influence its utilization which is expressed in the resulting productivity over time at the object may be much longer $[2,8,9,10]$.

Specifically, this can be shown on the example of single-bucket universal excavator. The following excavation work is required at the site: vertical land leveling of the surface layer, 
excavation of soil in a construction pit and excavation of several trenches, to loosen several lenses of firm soil, and to fill up hollows. Moreover, these works can be carried out only consequently and it is not economical to involve additional equipment for loosening, for example, a bulldozer-ripper. Hence the need to use the following changeable work equipment: front shovel, backhoe shovel, hydraulic hammer, grappler. The excavator can be used with all this equipment. This should be considered when calculating the work of the excavator on the object. In addition, we should consider not only the operational performance in volume of work of the machine, but also the use of the machine over time.

When determining the need of construction machines for the object, it is necessary to select machines based on the area of their rational use [4,5, 6,7]. One significant difference in the calculation of need of machines or volume is to determine the actual production of machines, in relation to a specific object.

The optimality of choosing a particular type of machine in comparison with other types of machines can be justified by use of these machines in rational areas defined by equations of equal costs.

Calculation of needed construction machines for the mechanization department should be carried out for a year in advance. Only if there is accurate data on the volume and structure of works for a longer period (2-3 years), the calculation can be performed on the same term with subsequent annual updating of demands based on specific planned tasks considering the structure the works such as, for example, earth excavation in table. 1.

Table 1. The earth excavation

\begin{tabular}{|c|l|c|c|}
\hline \multirow{2}{*}{$\mathrm{N}$} & \multirow{2}{*}{$\begin{array}{l}\text { Technological methods of works } \\
\text { production }\end{array}$} & \multicolumn{2}{|c|}{ In \% to total volume } \\
\cline { 2 - 4 } & $\begin{array}{l}\text { Tractors with mounted excavating } \\
\text { equipment }\end{array}$ & 2,2 & Recommended \\
\hline 2 & Single-bucket excavator & 37,6 & 2 \\
\hline 3 & Continuous bucket excavator & 3,3 & 7,9 \\
\hline 4 & Scrapers & 9,4 & 13,6 \\
\hline 5 & Bulldozers & 40,4 & 32,2 \\
\hline 6 & Land grader & 1,3 & 2,6 \\
\hline 7 & Single-bucket loaders & 1,1 & 2,6 \\
\hline 8 & Other means of mechanization & 4,2 & 5 \\
\hline 9 & Manually & 0,5 & 0,3 \\
\hline
\end{tabular}

The need for the mechanization department in the means of mechanization is formed based on requests requiring machines for construction sites, as well as to perform unscheduled works (reserve) and works in production base of construction, which can be determined by analogy of the past period. In accordance, the need for machines in mechanization department should be determined by method of optimization of the fleet structure or by using aggregate-based indicators, accounting the analysis of work in the base period (at least 3 years).

The peculiarity of determining the need for construction machinery for a ministry (department) is that it is defined for the construction industry without reference to a certain construction object according to the demand norms with a certain adjustment depending on the level of mechanization of construction for a given period. The need is determined by the annual amount of construction \& installation work in monetary terms. It does not specify a specific model of the machine which is replaced by an average machine of the fleet, which is determined by the sum of the main parameters of the machines $\left(\mathrm{m}^{3}\right.$-bucket capacity, $\mathrm{t}$ loading capacity, etc.). The norms on which the need is determined have a directive nature and are set for a period of 3-5 years. When calculating norms of the need of construction 
machines construction indicators (specific physical quantities, the structure of means of mechanization and the annual output of cars) are determined accounting the probabilistic nature of changing during the planning period, based on the analysis of these indicators in the base period. These standards consider the need of ministries (authorities) in the means of mechanization, taking into account the relocation of construction machines from one site to another, being on repair, reserve of machinery to perform unscheduled work, etc.

When planning construction indicators, trends in the development of mechanization work in the planned period are considered, during which standard norms will be taken into account. Concluding from the above, when calculating the need for construction machinery, as the hierarchical level of the organization for which calculation is done, increases, accuracy of the calculation reduces while the complexity of the task increases.

Calculation of the need for construction machines is carried out in the following sequence: the amount of work to be conducted is identified; the structure of mechanization means is determined; the operational hourly productivity of machines is calculated; the required number of machines to perform the specified volumes of work is calculated [1].

Calculating the number (need) of construction machines $\mathrm{N}$ using the formula:

$$
N=\frac{Q}{b_{e c h} * T_{t}}
$$

where Q- amount of given type of work in kind; $b_{\text {ech }}$ - operational productivity of the machine when performing the given type of work; $T_{t}$ - duration of work of the machine on the given type of work, mach.- h.

The duration of work of the machine on the given type of work is determined by the formula (10):

$$
T_{t}=\frac{\left(T_{d v}-d_{n B}\right)}{\frac{1}{t_{s m} * k_{s m}+D T_{p}}},
$$

where $\mathrm{T}_{\text {дв }}$ - specified duration of operation of the machines as determined from the schedule, days;

$t_{\mathrm{sm}}$ - average duration of shifts, $h$,

$\mathrm{k}_{\mathrm{sm}}$ - average shift factor of the machine;

$\mathrm{dnB}$-average duration to relocate the machine, days; hour.

DTp - duration of stay of machine in maintenance and repair (TM and R), days/mach -

Duration of the machine in maintenance and repair is defined per " Recommendations..."[3]

$$
D T_{p}=\left(\left(\frac{T_{p}}{t_{01}}-\frac{T_{p}}{t_{02}}\right) * d_{01}+\left(\frac{T_{p}}{t_{02}}-\frac{T_{p}}{t_{r m}}\right) * d_{02}+\left(\frac{T_{p}}{t_{r m}}-1\right) * d_{r m}\right) * \frac{K_{h}}{t_{r m}},
$$

where $\mathrm{T}_{\mathrm{p}}$ - average life until first major repair, Moto-h;

$\mathrm{t} 01, \mathrm{t} 02, \mathrm{t}_{\mathrm{rm}}$ - period of technical maintenance (TM) and a running maintenance (RM), Moto-h; d01; d02; $\mathrm{d}_{\mathrm{rm}}$-duration of stay of machines in and TM and RM, days;

$\mathrm{K}_{\mathrm{h}}$-coefficient of conversion Moto-h in mach.- $\mathrm{h}$.

The specified duration of the machine in accordance with the schedule is determined by the formula: 


$$
T_{d v}=\left(T_{d}-D_{v}\right) *\left(1-\frac{D_{1}}{T_{d}}\right),
$$

where $\mathrm{T}_{\mathrm{d}}$-planned schedule of construction of the site (calendar), days; $\mathrm{D}_{\mathrm{v}}$-number of days off; $\mathrm{D}_{1}$ - number of days with unfavorable weather conditions.

When determining the need of universal machines of one size which perform two or more given types of work, the calculation is carried out according to the formula:

$$
N_{0}=\sum_{i=1} N_{i}=\sum \frac{Q_{i}}{b_{e c h i}} * T_{v i},
$$

where $\mathrm{Ni}$ - the need for machines on the i-th type of work; Qi - the amount of work i-th type in kind; $\mathrm{T}_{\mathrm{vi}}$ - duration of operation of the machine at the $\mathrm{i}$-th type of work; $b_{\text {echi }}$ - hourly operational performance of the machine when conducting i-th type of work.

By using formulas (1) and (5) we can calculate the need for leading machines. The need for auxiliary or non-leading machines operating in the technological complex is calculated depending on the performance of the leading machine $[3,4]$.

The number of auxiliary machines relative to leading machines when the performance of machines is expressed in the same measuring units is calculated by the formula:

$$
N_{v s}=\frac{N_{0} * b_{e o}}{b_{e v}},
$$

$\mathrm{N}_{0}$ - number (need) of the leading construction machines;

$b_{\mathrm{eo}}, b_{\mathrm{ev}}$ - hourly operational performance leading and auxiliary machines respectively.

If the performance of the leading and auxiliary machines is expressed in different units, for example, concrete pump - concrete mixer truck, the need of auxiliary machines is determined by the formulas:

$$
N_{v s}=N_{0} * K_{p r} * \frac{b_{e o}}{b_{e v}},
$$

where $K_{\mathrm{pr}}$ - reduction coefficient of the dimension of performance from the auxiliary machine to the leading machine;

$$
N_{v s}=N_{0} * \frac{b_{e o}}{b_{e v p}},
$$

where $b_{p}$ - hourly operational performance of the auxiliary machine, presented in the measurement unit of performance of the leading machine.

For example, the algorithm for determining the operational performance of a concrete batching complex which works according to the technological scheme should be determined considering the delivery of the concrete mix, the performance of the concrete pump, measured in $\mathrm{m}^{3} / \mathrm{h}$.

To ensure the delivery of concrete, concrete mixers are used. The main feature of concrete mixers is the capacity of the drum (bunker) $\mathrm{m}^{3}$. The capacity of the mixer truck to deliver material from the place of manufacture to the construction site is determined by the formula:

$$
B_{e v}=\frac{V}{t_{r}+t_{n}+\frac{S}{V_{t r}}+\frac{S}{V_{p}}+t_{m}},
$$

$\mathrm{V}$ - volume of the concrete mixer truck $\mathrm{m}^{3}$ -

$t_{r}, t_{p}$-time to unload and load concrete $h$, 
$\mathrm{S}$ - the distance from the object to the place of unloading, $\mathrm{km}$;

$\mathrm{V}_{\mathrm{tr}}, \mathrm{V}_{\mathrm{p}}$ - the speed of the concrete mixer truck when loaded and empty $\mathrm{km} / \mathrm{h} ; \mathrm{T}_{\mathrm{m}}$-time for manoeuvring, h. (according to the guidelines to determine the need for basic construction machines, TSNIOMTP, 1989)

\section{Conclusions}

During the development of organizational and technological documentation (Construction method statement, work execution design, method statements), the choice of the main machines and calculation of their number should be derived using the recommendations and formulas given in the article.

\section{References}

1. M. N. Yershov [etc.] Organizational technology solutions at reconstruction of the public buildings which are in the operation mode: The monograph (DIA publishing house, 2013)

2. B.V. Zhadanovsky, S. A. Sinenko [and others] development of the projects of organization of construction of industrial buildings and structures: Proc. textbook, (Moscow, Publishing DIA, 2016)

3. B.V. Zhadanovsky, S. A. Sinenko. International Journal of Applied Engineering Research. 11(3) 1724-1727. (2016)

4. S. A.Mommy, B. V. Zhadanovsky, S. A. Sinenko. Scientific review. 17, 84-89. (2015)

5. B.V. Zhadanovsky, S. A. Sinenko. Scientific review, 9-2, 435-438. (2014)

6. B.V. Zhadanovsky, S. A. Sinenko, S.A. Mamochkin. European Conference on Innovations in Technical and Natural Sciences 7th International scientific conference. Austrian Journal of Technical and Natural Sciences. 5-6, 3-8. (2015)

7. B.V. Zhadanovsky, S. A. Sinenko. Visualization of design, organization of construction and technological solutions. Computing in Civil and Building Engineering Proceedings 2014 International Conference. pp. 137-142. (2014)

8. A. Volkov, V. Chulkov, R. Kazaryan, S. Sinenko. Applied Mechanics and Materials. 584-586. pp. 2681-2684. (2014)

9. S. A. Sinenko, A. M. Slavin. Scientific review. 1. S. 98-103. (2016)

10. B.V. Zhadanovsky, S.A. Sinenko, M.F. Cuzin. Technology and organization of building production. 1. p. 38-40. (2014) 